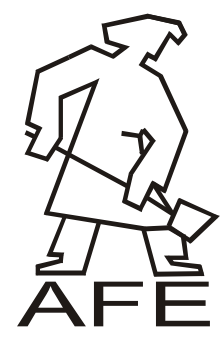

DOI: 10.2478/afe-2013-0073

\title{
The Influence of Impurities in Feed Ingots on the Quality of Castings Made from Nickel Superalloy IN-713C
}

\author{
F. Binczyk ${ }^{\mathrm{a}}$ *, J. Cwajna ${ }^{\mathrm{b}}$, M. Sozańska ${ }^{\mathrm{b}}$, P. Gradoń ${ }^{\mathrm{a}}$ \\ ${ }^{a}$ Department of Materials Technology \\ ${ }^{\mathrm{b}}$ Department of Materials Science \\ Silesian University of Technology, Krasińskiego Str. 8, 40-019 Katowice, Poland \\ * Corresponding author. E-mail address: franciszek.binczyk@polsl.pl
}

Received 13.06.2013; accepted in revised form 02.09.2013

\begin{abstract}
The paper presents the results of research on the impact of impurities in the feed ingots (master heat) on the precipitation of impurities in the ATD thermal analysis probe castings. This impurities occur mostly inside shrinkage cavities and in interdendritic space. Additionally, insufficient filtration of liquid alloy during pouring promotes the transfer of impurities into the casting. The technology of melting superalloys in vacuum furnace prevents the removal of slag from the surface of molten metal. Because of that, the effective method of quality assessment of feed ingots in order to evaluate the existence of impurities is needed. The effectiveness of ATD analysis in evaluation of purity of feed ingots was researched. In addition the similarities of non-metallic inclusions in feed ingots and in castings were observed.
\end{abstract}

Keywords: ATD, Superalloys, Feed ingot, Master heat, Solidification, Non-metallic inclusions

\section{Introduction}

The performance of aircraft engine components depends on macro- and microstructure shaped during solidification of casting and on the presence of non-metalic impurities evolving mostly in the last stage of solidification [1]. Nickel and cobalt superalloys are contaminated mostly with non-metallic precipitates and gases.

During melting process different impurities may pass to the liquid alloy. The most common sources of these are:

- contaminated feed materials,

- $\quad$ ceramic crucible material,

- $\quad$ contaminated mould cavity,

- $\quad$ products of reaction between the molten metal and mould materials, particularly when pouring temperature is high.
Nickel superalloys melting technology, due to closed furnace chamber, prevents any refining processes, slag removal etc. Therefore, each of aforementioned factors can lead to contamination of casting with non-metallics and gases. These phenomena may consequently lead to shrinkage porosity and nonmetallic inclusions, especially at grain boundaries.

Most non-metallic impurities have low freezing point and crystallize last. This causes their accumulation at the front of solidification and formation of eutectics. The composition of this eutectics often include impurities present in the shrinkage cavities and porosities of feed ingots (so-called "master heat"). These eutectics reduce operational properties of castings. Moreover, during the high temperature heat treatment of castings (e.g. aircraft engine turbine blades), melting and re-dissolution of these constituents in the eutectic matrix may lead to a significant 
increase in shrinkage microporosity. These processes are associated with the release of energy (exothermic processes) and therefore can be analyzed by ATD thermal analysis [2-4]. Particularly valuable for this analysis are information that can be read from the graph of the derivative $\mathrm{dT} / \mathrm{dt}$. The effects of the release of even small quantities of heat, that do not cause visible changes in the shape of the graph $\mathrm{T}=\mathrm{f}(\mathrm{t})$, are visible as collapses, inflections and stops on the graph of the derivative. A particular advantage of the ATD method is the short time in which the data for the quality assessment of feed ingots can be obtained [5-7].

\section{Research problem}

For the majority of nickel alloys, four main stages can be distinguished on the ATD graphs. They are shown in Figure 1 on the example of a cylinder $(\varphi 40 \times 100 \mathrm{~mm})$ cast from the IN-713C alloy.

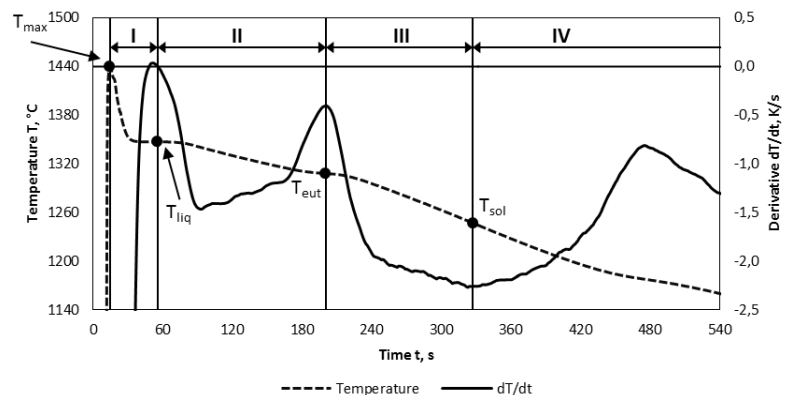

Fig.1. Main stages of solidification and cooling of IN-713C alloy casting

In stage $I$, from $T_{\max }$ to $T_{\text {lik }}$ (points $A$ to $B$ ), the $A T D$ graphs can provide information about the process of the formation of the nuclei of crystallisation (the effect of modification, primary carbides).

In stage II, from $T_{\text {lik }}$ to $T_{\text {Eut }}$ (points $B$ to $D$ ), the ATD graphs are the basis for quantitative evaluation of the metal matrix composition ( $\gamma$ phases, eutectics composed of carbides + intermetallic phases).

In stage III, from $T_{E u t}$ to $T_{\text {sol }}$ (points $D$ and $E$ ), the ATD graphs can serve as a point of reference for the evaluation of alloy "purity". The presence of gas and impurities in the melt usually leads to the formation of low-melting point eutectics, the occurrence of which considerably prolongs the duration of the final stage of solidification and reduces the value of the $\mathrm{dT} / \mathrm{dt}$ derivative (the rate of temperature decrease).

In stage $\mathbf{I V}$, from $\mathrm{T}_{\mathrm{sol}}$ to $\mathrm{T}_{\mathrm{ot}}$ (from point $\mathrm{E}$ ), the ATD graphs allow judging about the phase transformations that take place already in the solid state.

The first examination of the solidification curve of nickel alloys has already indicated that the ATD analysis is a good tool in evaluating the metallurgical quality of these alloys [7-9]. Analysis of derivative chart, illustrating the rate of decrease in temperature, makes possible to qualitatively evaluate the effect of non-metallic inclusions and gases in the alloy.

\section{Materials and methods of investigation}

Studies of the presence of non-metallic inclusions were conducted on master heat ingots and ATD probe castings made from the IN-713C nickel alloy with an average content of $0.03 \%$ Co, $13.26 \% \mathrm{Cr}, 5.85 \% \mathrm{Al}, 4.10 \% \mathrm{Mo}, 0.85 \% \mathrm{Ti}, 2.27 \%$ ( $\mathrm{Nb}+$ $\mathrm{Ta}$ ), and in particular for the following supply batches:

1.IN-713C, PWA655, master heat No V1542 (CAPI)

2.IN-713C, PWA655V, master heat No 3V5677

3.IN-713C, PWA655, master heat No AV 5737 and 3V 5400

The ingot IN-713C (PWA655V, master heat No 3V5677) provided three samples taken from different heights (top, middle and bottom). In total, six samples were taken.

An example of the samples of feed ingots prepared for melting, with visible shrinkage cavities are shown in Figure 2.
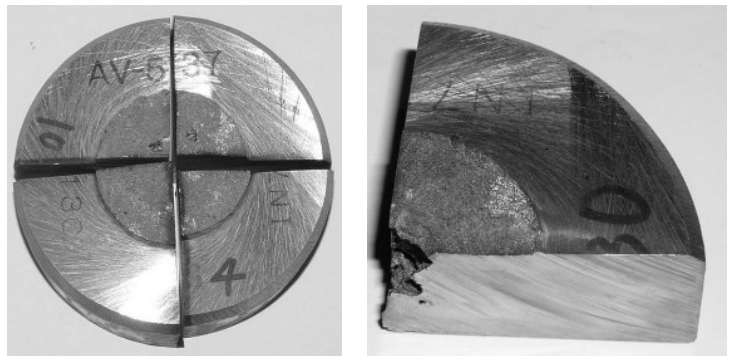

Fig. 2. Feed ingot (master heat AV5737) - visible shrinkage cavities in the axis of the ingot

Samples of cross-sections weighing about $1 \mathrm{~kg}$ were melted in an induction VIM furnace Balzers VSG-02 using an $\mathrm{Al}_{2} \mathrm{O}_{3}$ crucible which, thanks to the stability of the technological parameters, is suitable to melting of high-purity materials.

Melting was carried out in a vacuum of about $10^{-3}$. Prior to pouring, the volume of the furnace was filled with argon. Pouring was conducted under an argon atmosphere at the pressure of about $900 \mathrm{hPa}$. The test casting was designed in the shape of a cylinder of dimensions $\varphi 30 \times 120 \mathrm{~mm}$ with the $40 \times 45 \times 17 \mathrm{~mm}$ sprue head.

Thermocouples ware placed at a height of $40 \mathrm{~mm}$ in the moulds adapted to the tests from the moulds made by lost wax process in the WSK Rzeszów. Pt-PtRh10 thermocouple wires, 0.5 $\mathrm{mm}$ thick, were shielded inside the quartz tubes embedded in the mould wall. View of the mould inside the induction furnace chamber is shown in Figure 3

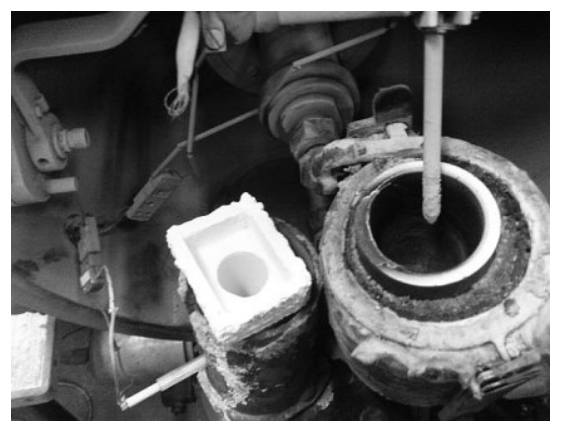

Fig. 3. Chamber of VSG-02 induction furnace 


\section{The results of investigations and discussion of results}

Dendrites in the shrinkage cavity and non-metallic inclusions in interdendritic spaces are shown in Figures 4 and 5.

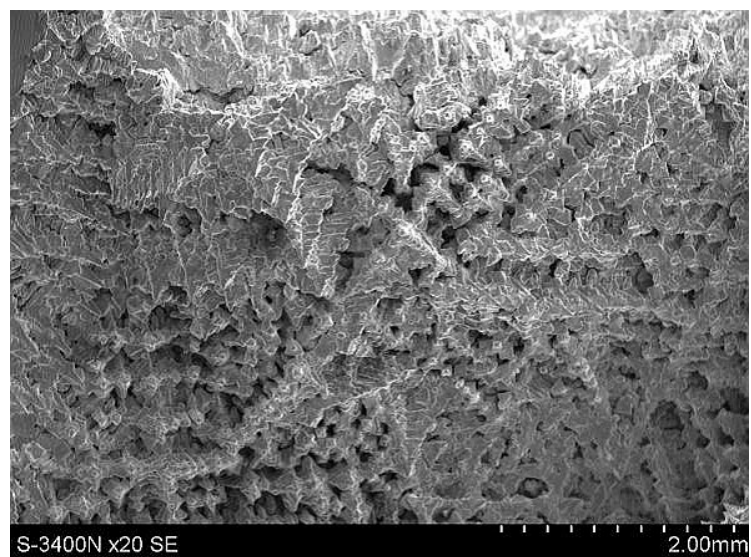

Fig. 4. Dendrites on the surface of the shrinkage cavity

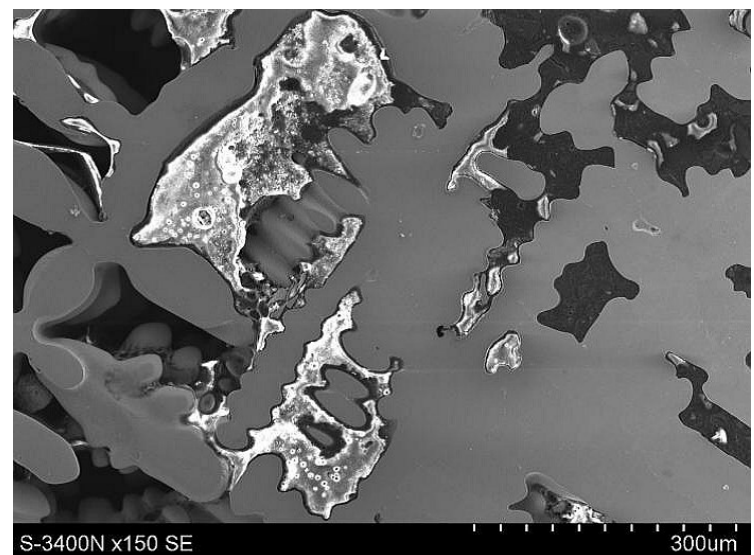

Fig. 5. Non-metallic inclusions in interdendritic spaces in the shrinkage cavity

Observation of the microstructure and chemical composition microanalysis were carried out on Hitachi scanning electron microscope $\mathrm{S}-3400 \mathrm{~N}$ coupled with EDS X-ray microanalysis systems, Thermo Noran, equipped with a software System Six. The sample results of these tests are shown in Figure 6.
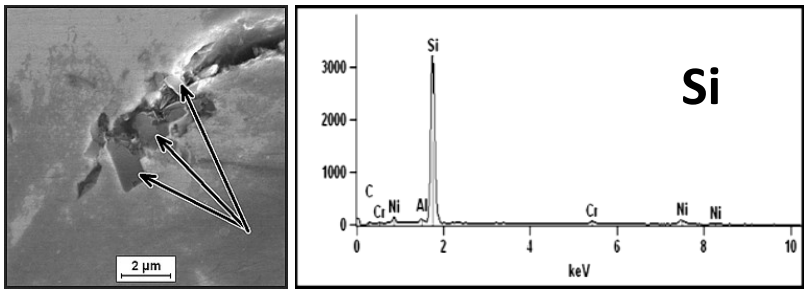

Fig. 6. Non-metallic inclusions in the shrinkage cavity
Research revealed numerous non-metallic inclusions, mainly silicates, in the interdendritic spaces. Traces of magnesium were detected on the surfaces of shrinkage cavities. Cross sections of shrinkage cavities were very porous. In the pores, inclusions containing oxygen and $\mathrm{Si}, \mathrm{Al}$ and $\mathrm{Mg}$ were found.

Figure 7 and 8 show examples of ADT graphs for analysis of feed ingots (master heat) with good and bad metallurgical quality. The presence of non-metallic impurities, forming a eutectic systems, change the character of the ATD graph before the end of solidification. Mainly, it lowers the temperature $T_{\text {sol }}$, increases the difference $\left(\mathrm{T}_{\text {eut }}-\mathrm{T}_{\mathrm{sol}}\right)$ and extends solidification time.

For standard test conditions, in the case of an IN-713C alloy, following parameters indicate good metallurgical quality: temperature $\mathrm{T}_{\text {sol }}$ is above $1225^{\circ} \mathrm{C}$, the difference $\left(\mathrm{T}_{\text {eut }}-\mathrm{T}_{\mathrm{sol}}\right)$ is less than $60^{\circ} \mathrm{C}$ and the time of the last stage of solidification is under $50 \mathrm{~s}$.

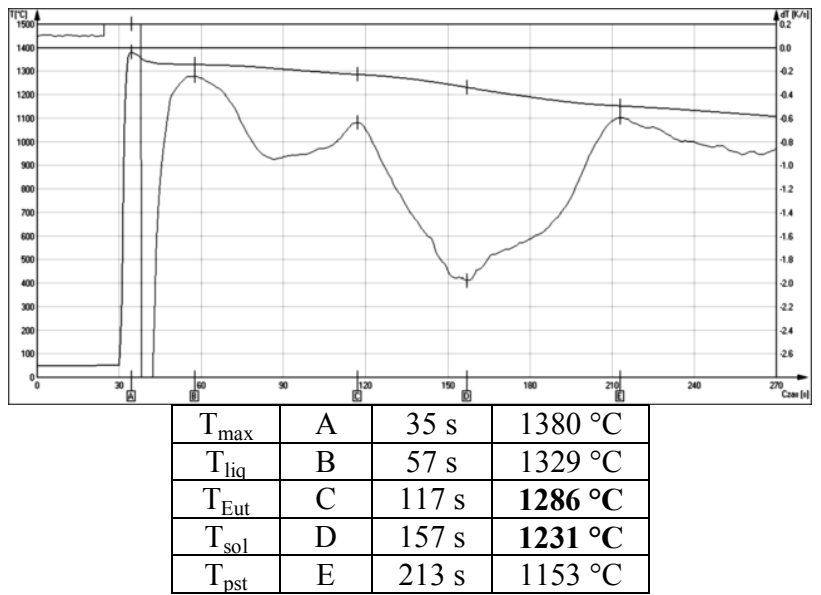

Fig. 7. ATD analysis of IN-713C (PWA655V, master heat No 3 V5677) with good metallurgical quality

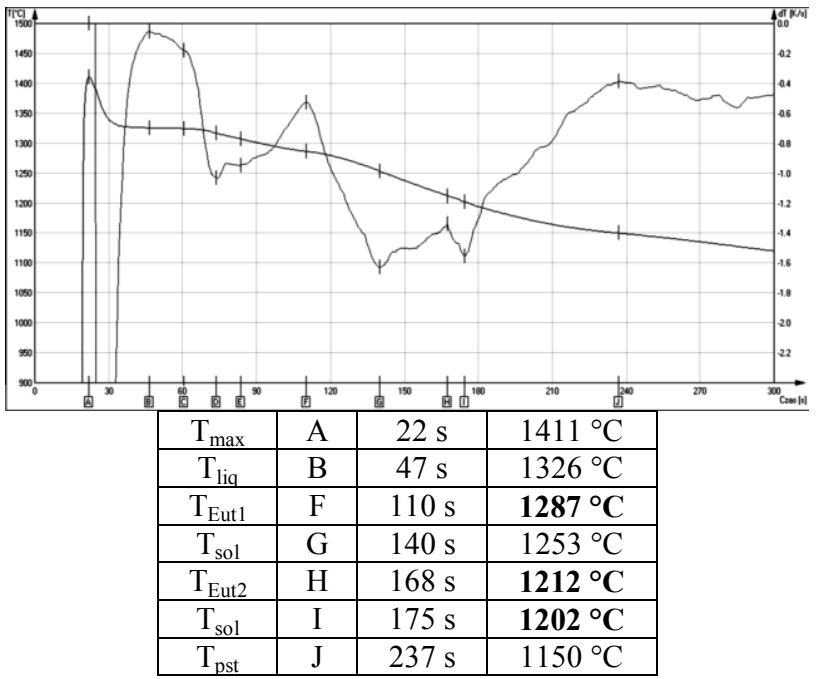

Fig. 8. ATD analysis of IN-713C (master heat No 3V5400) with bad metallurgical quality 
EDX analysis show the presence of non-metallic inclusions on the surface of the ATD probe casting, results are shown in Figure 9.

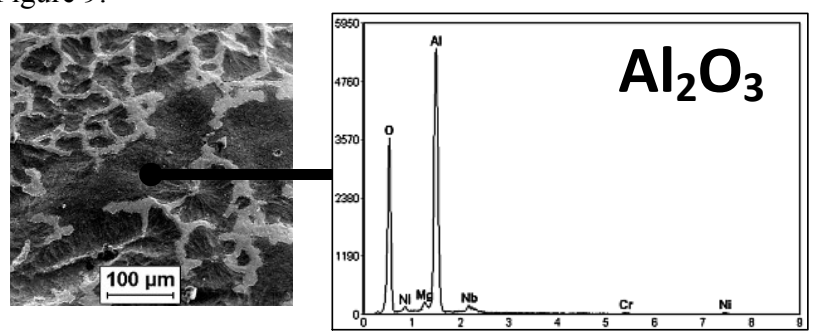

Fig. 9. X-ray microanalysis of dark spots on the surface of the ATD probe casting

\section{Conclusions}

ATD thermal analysis can be a useful tool to rapidly assess the quality of feed ingots (master heat). It is especially useful for detecting the presence of metallic impurities present in the pores and shrinkage cavities. The presence of non-metallic impurities, forming a eutectic systems, change the character of the ATD graph before the end of solidification. Mainly, it lowers the temperature $T_{\text {sol }}$, increases the difference $\left(T_{\text {eut }}-T_{\text {sol }}\right)$ and extends solidification time. For the standard test conditions, in the case of an IN-713C alloy, following parameters indicate good metallurgical quality: temperature $\mathrm{T}_{\text {sol }}$ is above $1225^{\circ} \mathrm{C}$, the difference $\left(\mathrm{T}_{\text {eut }}-\mathrm{T}_{\text {sol }}\right)$ is less than $60^{\circ} \mathrm{C}$ and the time of the last stage of solidification is under $50 \mathrm{~s}$. Numerous non-metallic inclusions, mainly silicates containing the $\mathrm{Ca}, \mathrm{K}, \mathrm{Fe}$ were found in the interdendritic spaces. Traces of magnesium were detected on the surfaces of shrinkage cavities. Cross sections of shrinkage cavities were very porous. In the pores, inclusions containing oxygen and $\mathrm{Si}, \mathrm{Al}, \mathrm{Mg}, \mathrm{Ca}, \mathrm{K}$ and $\mathrm{Na}$ were found.

\section{Acknowledgements}

Financial support of Structural Funds in the Operational Programme - Innovative Economy (IE OP) financed from the European Regional Development Fund - Project "Modern material technologies in aerospace industry",

No. POIG.01.01.02-00-015/08-00 is gratefully acknowledged.

\section{References}

[1] Chmiela, B., Sozańska, M. \& Rodak, K. (2012). Phase identification in nickel-based superalloys using EBSD/SEM and electron diffraction in STEM; Solid State Phenomena, $186,58-61$.

[2] Jura, S., Sakwa, J. \& Borek, K. (1980). The use of differential thermal analysis to determine the parameters of the chemical composition, Krzepnięcie Metali i Stopów, 2, PAN (in Polish)

[3] Binczyk, F. \& Krzemień, E. (1980). The use of differential curves coagulation studies cast iron crystallization, Mat. Konferencyjne Krzepnięcie Metali i Stopów, 23, PAN, Gliwice.

[4] Pietrowski, S. \& Władysiak, R. (1996). Control by TDA silumins piston, Krzepnięcie Metali $i$ Stopów, 28, PAN, Katowice.

[5] Binczyk, F., Śleziona, J., Szymszal, J. \& Gradoń, P. (2011). Effect of technological parameters on structure of castings made from IN-713C nickel alloy, Archives of Foundry Engineering, vol.11, Issue 4, 9-13. ISSN 1897-3310

[6] Binczyk, F., Śleziona, J. \& Mikuszewski, T. (2010). Effect of repeated remelting on the chemical composition and structure of nickel alloys, Archives of Foundry Engineering, vol.10, Special Issue 1, 189-194, ISNN 1897-3310.

[7] Binczyk, F., Śleziona, J., Cwajna, J. \& Roskosz, S. (2008). ATD and DSC analysis of nickel super alloys, Archives of Foundry Engineering vol. 8, Issue 3. 5-9, ISSN 1897-3310.

[8] Binczyk, F.\& Śleziona, J. (2010). The ATD thermal analysis of selected nickel superalloys, Archives of Foundry Engineering, vol.10, Issue 2, 13-19. ISSN 1897-3310.

[9] Binczyk, F., Śleziona, J. \& Gradoń, P. (2011). Ceramic filters for bulk inoculation of nickel alloy castings, Archives of Foundry Engineering, vol.11, Special Issue 3, 29-33, ISSN 1897-3310.

[10] Binczyk, F. (2012). Evaluation of metallurgical quality of master heat IN-713C nickel alloy ingots Archives of Foundry Engineering, vol.12, Issue 4, 5-11, ISSN 1897-3310 